\title{
Efficiency of the Halliwick Concept in the Rehabilitation of Children With Cerebral Palsy
}

\author{
Dragan Gajić, ${ }^{1}$ Slađana Jokić, ${ }^{1}$ Bogdana Mraković ${ }^{1}$
}

\section{Abstract}

Background/Aim: Since 2010, the Halliwick Concept has been applied in the rehabilitation of children with neurological disorders at the Department of Habilitation and Rehabilitation of Children and Youth at the Institute for Physical Medicine and Rehabilitation (IPMR) "Dr Miroslav Zotović" in Banja Luka, the Republic of Srpska, Bosna and Herzegovina. Aim of this study was to analyse results of the implementation of the full Halliwick Concept programme over the period from 1 January 2016 to 1 January 2017 and points to the effectiveness of this type of hydrokinesitherapy. Methods: After analysing 40 patients with different diagnoses of neurological disorders: cerebral palsy (CP), arthrogryposis (AG), Down syndrome (DS), and central nervous system (CNS) injury, only patients with CP were represented due to the homogeneity of the diagnosis and were included in analysis $(\mathrm{N}=30)$. Rehabilitation treatment of patients according to the Halliwick concept was performed, over a period of one year, for 60 minutes once a week. Patients were tested by Swimming With Independent Measurement (SWIM) test, Gross Motor Function Measure (GMFM) and Barthel Index before and after treatment.

Results: Considering all patients, before and after the application of the concept of individual Halliwick swimming skills/movement in water, a statistically significant difference was detected by assessing the SWIM test and a highly significant difference was detected by evaluating the Gross motor function measure test of GMFM66 , as well as in evaluating the Barthel Index test. Assessment of swimming abilities through the SWIM test showed the least progression was in the ability in Getting out of the water, with the greatest progression in the ability in Breathing control. Conslusion: The Halliwick Concept programme at the Department for the Habilitation and Rehabilitation of Children and Youth, IPMR "Dr Miroslav Zotović" in Banja Luka is effective and the results indicate the need for its application in the rehabilitation of children with CP.

Key words: Hydrokinesitherapy; Halliwick concept; Swimming; SWIM test; Cerebral palsy.
(1) Department of Habilitation and Rehabilitation of Children and Youth, Institute for Physical Medicine and Rehabilitation "Dr Miroslav Zotović", Banja Luka, the Republic of Srpska, Bosnia and Herzegovina.
Correspondence: DRAGAN GAJIĆ

E: gidroni@yahoo.com

\section{ARTICLE INFO}

Received: 7 July 2020 Revision received: 29 July 2020 Accepted: 31 July 2020

\section{Introduction}

In children with neurological disorders, kinesitherapy is the most important procedure in their rehabilitation. Early diagnosis and early initiation of treatment are very important due to better results. For the rehabilitation of move- ment disorders, it is important to determine the functional capacity of the musculoskeletal apparatus. Although there are various kinesitherapy methods, and they are the basis for the treatment of movement, coordination and movement disor- 
ders, the most popular method is Bobath. More recent research indicates that the Bobath treatment is not overly better than other treatments in patients after stroke. ${ }^{1}$

In the literature related to medical rehabilitation of patients, the Halliwick concept is not present as a kinesitherapy method in general. Of the many approaches to the rehabilitation of children with special needs, the most important connection is between the Halliwick and Bobath concepts. The Halliwick concept is unofficially referred to as "Bobath in the Water". Both concepts began to develop in England in the middle of the last century, out of need for a different approach when working with children with neurodevelopmental and motor impairments. ${ }^{2}$

The Halliwick concept focuses on the biophysical principles of movement in water, especially the developmental sense of equilibrioception and fundamental stability. The Halliwick concept approaches teach all people in water activities, but it is especially focused on people with physical and/or mental disabilities, and their ability to move independently in water and, depending on ability, even to swim. ${ }^{3}$ Kinesitherapy in combination with hydrokinesitherapy is the basic and most important form of treatment for children with $\mathrm{CP}$, because the exercises are safe, simple and fun for them, indicating that the Halliwick concept is essential in their rehabilitation. ${ }^{4}$

In order to ensure long-term gross motor function improvement in children with CP, Ballington and Naidoo indicated that water-based programmes should be integrated and considered as an essential, ongoing mode of treatment for these children together with conventional therapies. ${ }^{5}$ Researchers Christodoulaki et al claimed that water-based programmes in therapy of children with CP produced positive effects on children's respiratory system. ${ }^{6}$

Iranian researchers Khalaji et al published a comprehensive review of 33 research papers published from 2000 to 2016 on the results of hydrotherapy on patients with $\mathrm{CP}$ and concluded that this therapy, when applied in conjunction with other conventional therapies, has positive effects in all areas of the International classification of functioning, disability and health. ${ }^{7}$
The Halliwick concept improved motor function in children with CP and autism in swimming and gross motor skills depending on the individual condition of the patient. ${ }^{8}$ Meyer et al concluded that for children with cerebral palsy, Halliwick therapy provided significant results in a global reduction in spasticity. ${ }^{9}$

Researcher Sršen, showed that the Swimming with Independent Measurement (SWIM) test was sensitive to changes in swimming abilities in patients..$^{10}$ Progress was noted in all patients tested. The SWIM test provides a detailed analysis of the swimmer's ability and allows accurate preparation of further activities for the purpose of the swimmer's progress. In preparation planning, it is essential to choose the tasks and activities that follow in order of difficulty. ${ }^{10}$

After the swimming program there is statistically significant effect on walk improvement, running and jumping as well as on the overall gross motor function of children with CP. Also, the statistically significant impact is on the increase of mental adaptation to the water environment, ability to move independently in water and ability of these children to swim. ${ }^{11}$

Researcher Tripp shown first clinical trial of aqueous physiotherapy in post-acute stroke patients in a hospital setting. They showed greater improvements in postural stability and functional walking ability after two weeks of intervention compared to conventional treatment. Further studies indicate that larger sample sizes and longer duration of therapy are necessary. ${ }^{12}$

In a case study from the University of Central England, the assessment was performed by SWIM and the Gross motor function measure (GMFM) tests and the therapy led to improvements in balance and dynamic systems in theoretical frameworks. Additional benefits of swimming included improved ability to maintain an appropriate level of fitness, integration with peer group and increased confidence. ${ }^{13}$

Since 2010, the Halliwick concept has been applied within the rehabilitation of children with neurological disorders at the Department of Habilitation and Rehabilitation of Children and Youth at the IPMR "Dr Miroslav Zotović" in Ban- 
ja Luka. The aim of this research was to present a retrospective analysis of the efficiency of the complete Halliwick concept program within the rehabilitation treatment of children with $\mathrm{CP}$ treated at the Department of Habilitation and Rehabilitation of Children and Youth at the IPMR "Dr Miroslav Zotović" in Banja Luka, during the period from 1 January 2016 to 1 January 2017.

\section{Methods}

Rehabilitation with the Halliwick concept was carried out for years on the same patients (children with neurological disorders) and five years after the start of the concept, in 2016, was chosen as a reference at the Department of Habilitation and Rehabilitation of Children and Youth at the Institute for Physical Medicine and Rehabilitation (IPMR) "Dr Miroslav Zotović" in Banja Luka, the Republic of Srpska, Bosna and Herzegovina. The efficiency of this concept on children with CP, who were treated in the mentioned institution was analysed. After analysing 40 patients with different diagnoses of neurological disorders: CP, arthrogryposis (AG), Down syndrome (DS), and central nervous system (CNS) injury, only patients with $\mathrm{CP}$ were represented due to the homogeneity of the diagnosis, and were included in analysis. The approval of the Ethics Committee of the IPMR "Dr Miroslav Zotović" Banja Luka for rehabilitation of patients as well as for analysis of data was obtained.

Rehabilitation treatment of patients according to the Halliwick concept was performed, over a period of one year, for 60 minutes once a week.

During this period, 30 patients with CP were examined (10 patients in 3 groups each, groups formed according to the characteristics of the patients who were at that moment registered for the mentioned rehabilitation and the maximum number of therapists - instructors working with the patients in the pool). The concept is performed by "one-on-one and all together". Age and gender of patients was recorded.

Upon admission to the aforementioned ward, patients underwent testing to determine their initial condition, prior to enrolment in rehabilitation treatment. All patients who were presented in this study were enrolled in kinesitherapy before the Halliwick concept of rehabilitation.

GMFM and Barthel index tests were performed in all patients prior to the application of the Halliwick concept and considered relevant for the initial condition of the patient, while for the SWIM test therapist / instructor derived input parameters at the beginning of the application. In this research the greatest attention was paid to the SWIM test as the only instrument for evaluating progress in the water movement, which is also a major rehabilitation feature of the Halliwick concept.

The SWIM test is intended to be a tool for assessing swimming abilities and analysis of movement in water of children with special needs and includes 11 abilities and movements, which are an integral part of the Halliwick Concept Ten Points program. Each movement has well-defined criteria that assess the ability in the range of 0 to 7 points. The maximum score can be 77 points. 14

The test includes the following abilities / movement in water:

A. Entering the water (with or without help)

B. Adaptation to water (movement with full support to independent movement in water)

C. Respiratory control (ability to exhale air over water to control breathing underwater)

D. Balance (from full support to self-sustaining floating position on the back in turbulent water)

E. Transversal rotation back (occupying a backfloat position from full support to self-rotation) F. Transversal rotation forward (from full support to self-rotation)

G. Sagittal rotation (from full support to self-rotation)

$\mathrm{H}$. Longitudinal rotation (from full support to independent rotation)

I. Combined rotation (from full support to independent rotation)

J. Swimming style development (from skating with support to solo swimming)

K. Getting out of the water (with or without help)

The Halliwick concept was introduced to promote joyful movements in water and swimming. To assess the swimming skills and advancement of an individual swimmer, in the Halliwick concept, SWIM was used as a valid and reliable mea- 
sure..$^{15}$ SWIM is an assessment tool and it is used to monitor swimmer progress as well as for research purposes. ${ }^{16}$

GMFM is a standardised instrument for measure a gross motor function in children with CP. The GMFM-88 test evaluates 88 motor function items in five areas: a) lying and turning, b) crawling and kneeling, c) sitting, d) standing, e) walking, running and jumping and is applicable to children with DS and code lesion of the central nervous system, while GMFM-66 was modified from 88-items and used to assess the ability of children with CP. All items are usually achieved in children 5 years of age with normal motor skills. ${ }^{17}$ Higher overall score, in GMFM-66 is indicating better motor function.

The Barthel Index monitors functional independence before and after treatment and the level of care required. It is intended for patients with long-term recovery but is also used as an evaluation measure. The Barthel Index can also be used for clinical assessment of function change as well as for research purposes. It is applicable to patients with neurological disorders. ${ }^{18}$ The test contains 10 variables / items that have been assigned a certain number of points, depending on the level and rank of the variable, which describe the activities of daily living and patient mobility. Higher scores are associated with a greater likelihood that a patient will be able to live in a home with a degree of independence after discharge from hospital. In determining the allocation of points for each item, the amount of time and physical assistance required to complete each item is required.

Comparative analysis of the results of patients with CP before and after the application of the Halliwick concept for the individual SWIM test swimming ability and the total scores of the tests SWIM, GMFM-66 and Barthel index was performed. Results of tests were presented with total number of points (score) of the SWIM test for all patients, individually, and for group of all patients in statistical parameters of minimum, maximum, median, arithmetic mean, standard deviation and statistical significance, using the program IBM SPSS, version 21.0.

\section{Results}

Data for thirty patients was analysed. There were 20 male and 10 female patients, from 5 to 18 years of age.

Patients were rehabilitated from year to year, and data was analysed for 2016. Total number of points, scored on the SWIM test, before and after the application of the Haliwick concept for one year is shown in Figure 1.

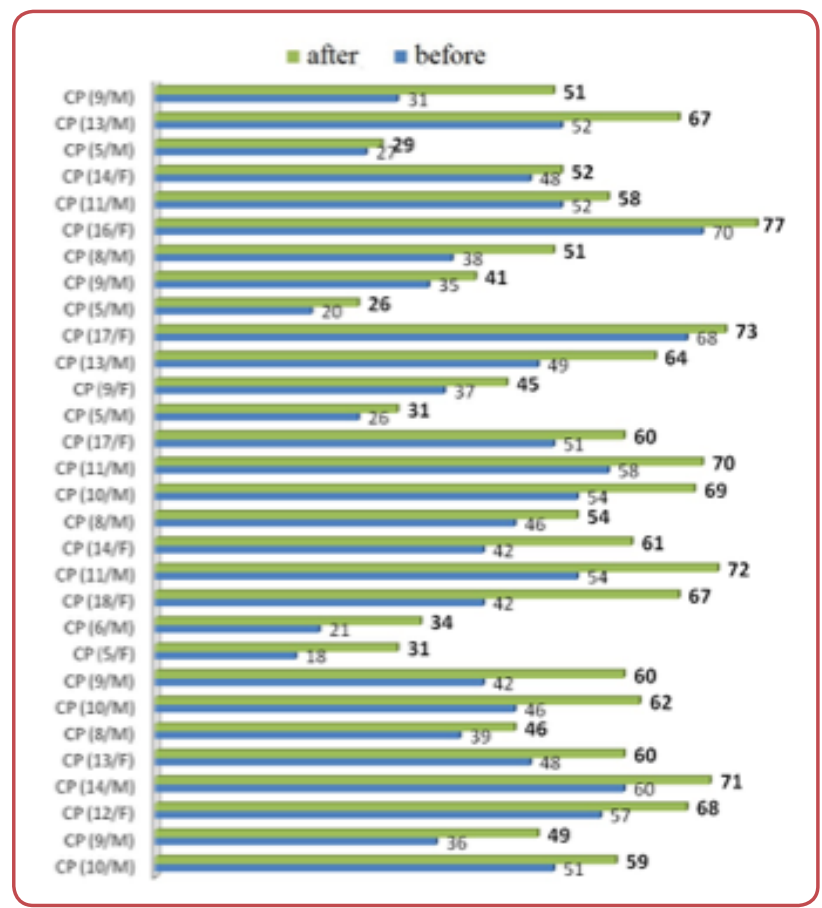

Figure 1. The total number of points (score) of the SWIM test before and after the application of the Halliwick concept program in all patients

Following the median value, which is used in the non-parametric tests, ability to Get out of the water (3.00) was lowest in individual swimming abilities in the SWIM test in patients with CP before applying the Halliwick concept. Also, same parameter remained at the same level after the application of the Halliwick concept (3.00). Highest ability of all individual abilities was Breathing control, before applying the Haliiwick concept amounted to 5.50, and after applying the Halliwick concept median was 7.00, which is shown in Table 1 and 2.

Comparison of the values of the medians and arithmetic means for the total score for the SWIM test before and after the Halliwick concept for CP patients (Table 1 and 2), showed the median in- 


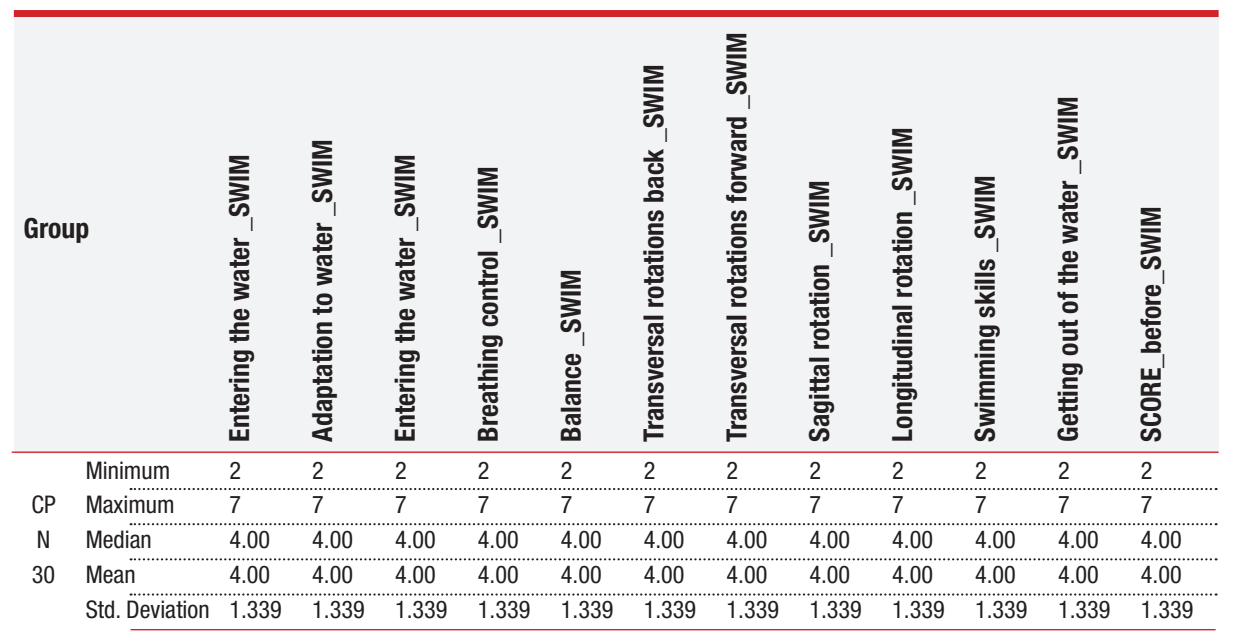

Table 1: Values of each swim ability and the total score in the SWIM test before Halliwick swimming therapy

crease of 13.5 (22.69\%), and mean increase of 11.34 , or $20.52 \%$.

Comparison of the values of the medians and arithmetic means for the total score for the GMFM-66 test before and after the Halliwick concept, Table 3, shows that there is no change in the median for CP patients, whereas for the arithmetic mean an increase of only 0.50 or $0.87 \%$.
Comparison of the values of the medians and arithmetic means for the total score for the Barthel index test before and after applying the Halliwick concept, Table 3, showed that there is a slight change for patients with CP for a median of 0.50 points, or 0.68 for the arithmetic mean.

Using the Wilcoxon Rank Test, Table 4, a highly statistically significant difference was detected

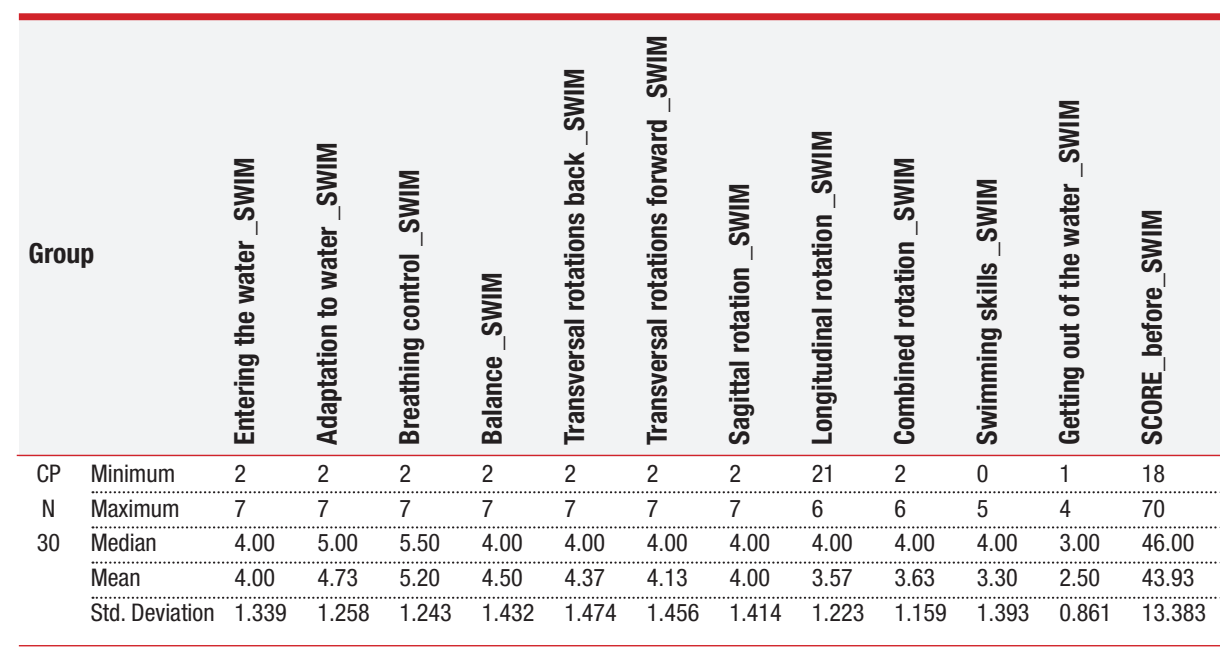

Table 1: Values of each swim ability and the total score in the SWIM test before Halliwick swimming therapy

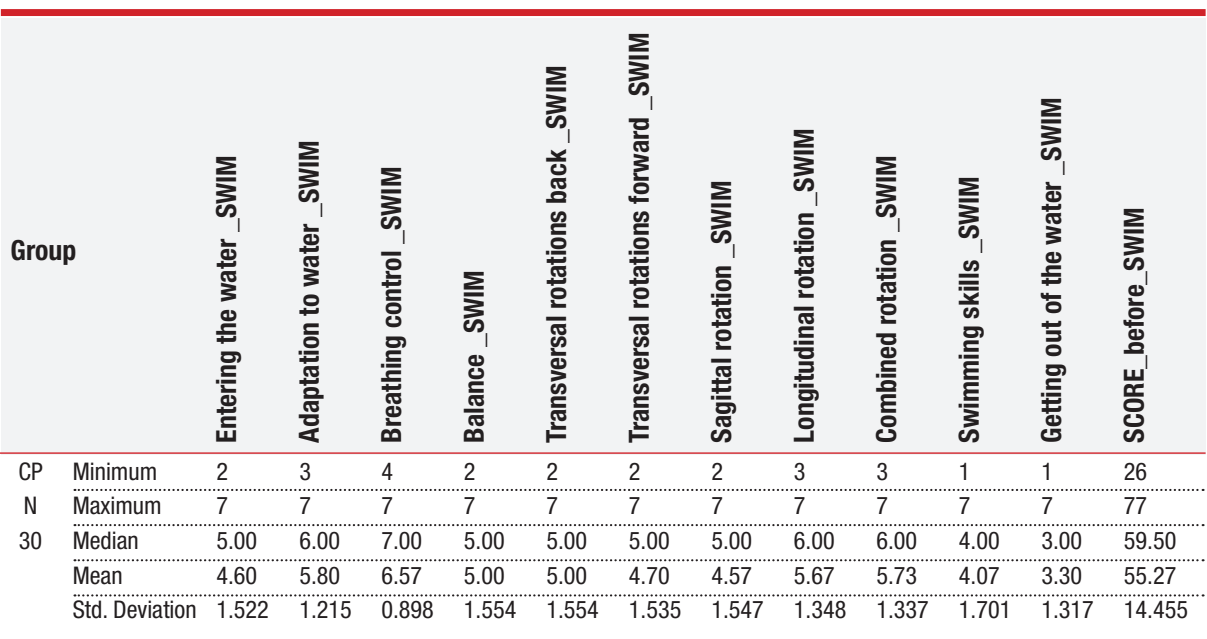

Table 2: Values of each swim ability and the total score in the SWIM test after Halliwick swimming therapy 


\begin{tabular}{|c|c|c|c|c|c|}
\hline Group & & before_GMFM_66 & after_GMFM_66 & before_Barthel_index & after_Barthel_index \\
\hline $\mathrm{CP}$ & Minimum & 21.25 & 22.35 & 25 & 25 \\
\hline N & Maximum & 89.07 & 90.26 & 99 & 99 \\
\hline \multirow[t]{3}{*}{30} & Median & 59.9200 & 59.9200 & 73.00 & 73.50 \\
\hline & Mean & 57.0107 & 57.5143 & 72.03 & 72.43 \\
\hline & Std. Deviation & 14.70908 & 15.04824 & 20.853 & 21.066 \\
\hline
\end{tabular}

Table 3: Values of the total score in the GMFM and Barthel index test before and after Halliwick swimming therapy

\begin{tabular}{|c|c|c|c|c|c|c|c|c|c|c|c|c|c|c|}
\hline Group & 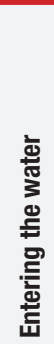 & 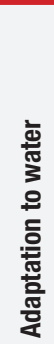 & 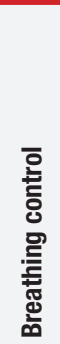 & 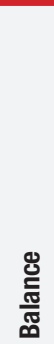 & 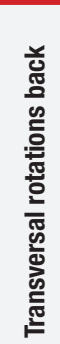 & 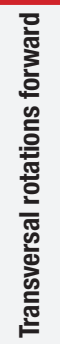 & 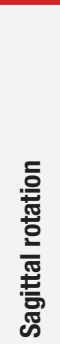 & 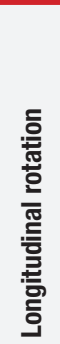 & 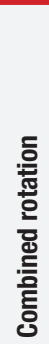 & $\begin{array}{l}\frac{\infty}{\bar{y}} \\
\text { s } \\
\text { o } \\
\text { 言 } \\
\text { 言 }\end{array}$ & 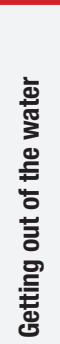 & 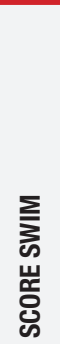 & $\begin{array}{l}0 \\
\sum_{0}^{1} \\
\sum_{0}^{1}\end{array}$ & 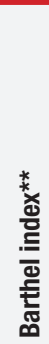 \\
\hline $\begin{array}{c}\mathrm{C} \\
\mathrm{P} \\
\mathrm{N} \\
30\end{array}$ & $\begin{array}{l}\text { *.0 } \\
\text { ơ } \\
0\end{array}$ & $\begin{array}{l}* \\
\text { o. } \\
0\end{array}$ & $\begin{array}{l}\text { * } \\
\text { Oे } \\
0 \\
0\end{array}$ & $\begin{array}{l}* \\
\text { o. } \\
0 \\
0\end{array}$ & $\begin{array}{l}\text { * } \\
\text { ô } \\
0 \\
0\end{array}$ & 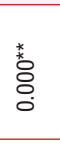 & $\begin{array}{l}\text { * } \\
\text { 。․ } \\
0\end{array}$ & $\begin{array}{l}\text { * } \\
\text { o } \\
0\end{array}$ & $\begin{array}{l}\text { * } \\
\text { Oे } \\
0\end{array}$ & $\begin{array}{l}\text { * } \\
\text { Oे. } \\
0 \\
0\end{array}$ & $\begin{array}{l}\text { * } \\
\text { Oे } \\
0\end{array}$ & $\begin{array}{l}\text { * } \\
\text { O̊. } \\
0\end{array}$ & $\begin{array}{l}\text { *. } \\
\text { o. } \\
0\end{array}$ & $\begin{array}{l}\text { * } \\
\text { 总 } \\
0\end{array}$ \\
\hline
\end{tabular}

Table 4: The significance of changes in swimming skills and the total score according to the SWIM test, GMFM-66 and Barthel index test Wilcoxon's Rank Test/

before and after applying the Halliwick concept of all individual swimming abilities / movement in water by evaluating the SWIM test in patients with CP $\left(\mathrm{p}<0.001^{* *}\right.$ for all individual swimming abilities, and for sagittal rotation with exactly $\mathrm{p}=0.001^{* *}$ ).

Looking at all patients with CP there were statistically significant difference before and after the application of the concept of individual Halliwick swimming skills / movement in the water SWIM assessment test, as well as the total number of points / SCORE.

In patients with $\mathrm{CP}$, a highly statistically significant difference was, before and after applying the Halliwick concept, when evaluating the gross physical (motor) ability test of GMFM-66 ( $p=$ $0.003^{* *}$ ) and estimating by the Barthel index test $\left(\mathrm{p}=0.006^{* *}\right)$, Table 4 .

\section{Discussion}

Assessment of swimming abilities through the SWIM test showed, in the entire sample of 30 patients before and after applying the Halliwick concept, the least progression was in the ability to Getting out of the water, with the greatest progression in the ability to Breathing control, as it was also confirmed by other research. ${ }^{4,6}$
The success of the application of the Halliwick concept is shown by the overall results. The average total score (following the median value for the non-parametric tests) for swimming ability assessment/movement analysis in water - SWIM before applying the Halliwick concept for patients with CP was 46.00 , and after applying the concept it was 59.50. In the whole sample of 30 patients the median increased after applying the Halliwick concept program by of 13.50 points $(22.68 \%)$ for the median, while 11.34 (20.51\%) for the arithmetic mean.

Results showed that in CP, but also in other neurological disorders there was progression, but that it is not uniform, due to the different sub-classification within their primary diagnosis, and it is also manifested differently on their swimming skills after applying Halliwick concept, which was confirmed mostly by other research as well. 5, 7,8,11

Using Wilcoxon Rank Test, with the SPSS, considering all patients, statistically significant difference $\left(p<0.001^{* *}\right)$ was detected before and after the application for the concept of individual Halliwick swimming skills/movement in water in total score on SWIM Test. Looking at all patients, a highly statistically significant difference was detected before and after applying the Halliwick concept by evaluating the Gross motor function measure test of GMFM-66 ( $\left.p=0.003^{* *}\right)$, which were confirmed by other studies. ${ }^{5,11}$ Highly significant difference was detected before and after applying the Halliwick concept by assessing the Barthel index test ( $p=0.006^{* *}$ ) which were not analysed by other studies. 


\section{Conclusion}

In children with $\mathrm{CP}$, the Halliwick concept adapts to the physical and mental abilities of the person and the results of the improvement are individual. According to the data from this study, the assessment of swimming abilities after application of concept is individual. Patients regardless of gender and age, within the same diagnosis, have different results.

The research confirmed most of the conclusions of other studies, that the application of the concept of the Halliwick program leads to the improvement of the patient's condition in certain swimming abilities. The overall results show that it is necessary to use this presented hydrokinesitherapy in the rehabilitation of patients with CP, because even a small improvement in any ability in such patients is of great importance.

\section{Acknowledgements}

None.

\section{Conflict of interest}

None.

\section{References}

1. Díaz-Arribas MJ, Martín-Casas P, Cano-de-la-Cuerda R, Plaza-Manzano G. Effectiveness of the Bobath concept in the treatment of stroke: a systematic review. Disabil Rehabil 2019 Apr;24:1-14.

2. Graham JV, Eustace C, Brock K, Swain E, Irwin-Carruthers S. The Bobath concept in contemporary clinical practice. Top Stroke Rehabil 2009 Jan-Feb;16(1):57-68.

3. IHA International Halliwick Association 2000 [cited 2016 Mar 15]. Available from: http://www.halliwick. org.

4. Valle M, Vo A, Liu H, Salem Y. Effectiveness of aquatic therapy interventions in the management of children with cerebral palsy: a systematic review. DMCN, 2017 [cited 2019 Apr 20]. Available from: https://onlineli- brary.wiley.com/doi/epdf/10.1111/dmcn.47 13512 .

5. Ballington SJ, Naidoo R. The carry-over effect of an aquatic-based intervention in children with cerebral palsy. Afr J Disabil 2018;7:a361, Available from: https://doi. org/10.4102/ajod.v7i0.361.

6. Christodoulaki E, Chandolias K, Hristara-Papadopoulou A. The effect of hydrotherapy - Halliwick concept on the respiratory system of children with cerebral palsy. BAOJ Pediat 2018,4(3):063.

7. Khalaji M, Kalantari M, Shafiee Z, Hosseini MA. The effect of hydrotherapy on health of cerebral palsy patients: an integrative review. Iran Rehabil J 2017;15(2):173-80.

8. Vascakova T, Kudlacek M, Barrett U. Halliwick concept of swimming and its influence on motoric competencies of children with severe disabilities. EUJAPA 2015;8(2):4449. doi: $10.5507 /$ euj.2015.008.

9. Meyer E, Fahkry A, Lambeck J. Comparison between a session of classical aquatic therapy and specific according to the Halliwick concept on the modification of spasticity in children with cerebral palsy. Turk J Physiother Rehab 2013;24(2):S88, Available from http://www.researchgate.net/publication/256752386.

10. Sršen A. Individualizacija rada u području obuke plivanja osoba sa invaliditetom. Proceedings of 12th Croatian Non-swimmer Training Counseling, Rijeka, Croatia, 2012. p. 26-31., Available from http://www.hrks.hr/ download/plivanje2012_zbornik.pdf.

11. Jorgić B, Dimitrijević L, Aleksandrović M, Okičić T, Madić $\mathrm{D}$, Radovanović $\mathrm{D}$. The swimming program effects on gross motor function, mental adjustment to the aquatic environment, and swimming skills in children with celebral palsy: a pilot study. Spec Eduk Rehab (Beograd) 2012;11(1):51-66. Available from: http://www.casopis. fasper.bg.ac.rs/izdanja/SEIR2012/vol11br1/1Spec_ Edu_i_Reh_ISTRAZIVANJA /04-Jorgic-Dimitrijevic-Aleksandrovic.pdf.

12. Tripp WF. Effekte der Bewegungstherapie im Wasser (Halliwick-Therapie) auf die Funktionelle Mobilitat bei Schlaganfallpatienten - eine Kontrrollierte, Randomisierte Studie. Master Thesis. Frankfurt am Main Department für Klinische Medizin und Präventionsmedizin - Zentrum für Klinische Neurowissenschaften an der Donau-Universität Krems; 2011. Available from: http://www.ewacmedical.com/html/stream_file. php\%3Fkey\%3D890dl45mn.

13. Mackinnon K. An evaluation of the benefits of Halliwick swimming on a child with mild spastic diplegia, case study. University of Central England, 2015; Available from: http://www.halliwick.org.uk/downloads/casestudy01.PDF.

14. Sršen KG, Vrečar I, Vidmar G. Halliwickov koncept učenja plavanja in ocenjevanje plavalnih veščin, Rehabilitacija 2010;9(1):32-9. Available from http://ibmi.mf.uni-lj.si/ rehabilitacija/vsebina/.

15. Sršen KG, Vidmar G, Pikl M, Vrečar I, Burja C, Krušec K. Content validity and inter-rater reliability of the Halliwick-concept-based instrument 'Swimming with Independent Measure'. Int J Rehabil Res 2012 Jun;35(2):11623. doi: 10.1097/MRR.0b013e32835277ab.

16. Peacock K. S.W.I.M. Swimming with Independent Measurement. Hull, UK: Halliwick Association of Swimming Therapy; 2006.

17. Russell DJ, Rosenbaum PL, Avery LM, Lane M. Gross Motor Function Measure (GMFM-66\&GMFM-88). User's Manual. London: Mac Keith Press; 2002.

18. Shah S, Vanclay F, Cooper B. Improving the sensitivity of the Barthel index for stroke rehabilitation. J Clin Epidemiol 1989;42:703-9. 